\title{
Involved-site Radiation Therapy
}

National Cancer Institute

\section{Source}

National Cancer Institute. Involved-site Radiation Therapy. NCI Thesaurus. Code

C153310.

A type of conformal radiation therapy in which the prechemotherapy gross tumor volume determines the clinical target volume, resulting in an irradiated volume that is significantly smaller than with involved-field radiation therapy. 